\title{
Paint Casting: A facile method of studying mineral electrochemistry
}

\author{
Andrew P. Abbott, ${ }^{* a}$ Francesca Bevan, ${ }^{a}$ Monika Baeuerle, ${ }^{a}$ Robert C. Harris ${ }^{a}$ and Gawen R. \\ T. Jenkin, ${ }^{\mathrm{b}}$ \\ ${ }^{a}$ Department of Chemistry, ${ }^{b}$ Department of Geology, University of Leicester, Leicester LE1 7RH, UK. \\ E-mail:apa1@le.ac.uk; Fax:+44(0)1162523789,
}

\begin{abstract}
The electrochemical properties of minerals are often difficult to study due to the need to maintain an electrical contact with the current collector. In this study it is shown that a paste of the powdered mineral can easily be made by mixing it with an ionic liquid and painting this onto an electrode surface. This enables voltammograms with high resolution and relatively low resistive artefacts to be obtained. The oxidative and reductive charge can be correlated to the loading of mineral on the electrode.
\end{abstract}

\section{Key Words}

mineral, galena, deep eutectic solvent, electrodissolution

\section{Introduction}

The issue with studying the electrochemistry of solid, conducting materials is maintaining electrical conductivity with the charge collector and the electrolyte. This study could refer to almost any conducting material but for the purpose of this article the mineral galena $(\mathrm{PbS})$ was used as a test substrate.

One method to study the electrochemistry of minerals is to have a single crystal contacted to an electrode using a conducting silver epoxy. The issue with this is that some minerals are poorly conducting and so there is usually a resistive artefact which decreases the resolution of the voltammogram to such an extent that very broad waves are usually obtained.

An alternative approach which has been used is to make a composite mixture of powdered mineral, with an inert conducting material such as graphite and an inert fluid such as a silicone oil. The components are usually ground into a paste which can be pressed into an electrode. These are laborious to make and can also lead to resistive artefacts. Practical issues usually limit the current collector to carbon [1]. A review of electrochemical analysis of solids has been carried out by Grygar et al. [2] and a database of the electrochemical properties of minerals and artists pigments has also been collated [3]. 
An alternative approach would be to isolate the powder within an inert, ion conducting medium which has an appropriate viscosity such that a paste forms which adheres to the electrode surface. In this case it is demonstrated that a conducting paste can be made by taking a powdered mineral and mixing it with an ionic liquid. Ionic liquids have been used extensively in electrochemical applications [4,5]. In the case of this paper, a deep eutectic solvent, DES will be used to form the conducting paste. DESs are mixtures of a quaternary ammonium electrolyte and a hydrogen bond donor such as urea or ethylene glycol [6]. They have been used for large scale electrochemical applications such as electrodeposition and electropolishing [7,8]. They are also being used for mineral [9] and metal oxide processing applications [10]. The relatively high viscosity of DESs and ionic liquids enables the paste to have the requisite properties to adhere the mineral to the surface of most electrode materials. The relatively high conductivity of the ionic liquid or DES reduces the resistive artefacts which are often characteristic of carbon paste electrodes. In the current investigation galena was chosen as the mineral to study as its electrochemistry in aqueous solutions has been widely reported $[11,12,13]$.

\section{Instruments and Experiments}

The DES used in all experiments was synthesised from a 2:1 molar ratio of ethylene glycol and choline chloride. The mixture (commonly known by its trade name of Ethaline) was stirred at $70^{\circ} \mathrm{C}$ until a homogeneous solution was observed. A paste was made by grinding 63 $\mathrm{mg}$ of galena to a particle size of $100 \mu \mathrm{m}$ with a pestle and mortar and mixing it with $106 \mathrm{mg}$ of a DES. The paste was applied to the surface of an electrode using a fine paintbrush.

Cyclic voltammetry (CV) experiments were carried out using an Autolab Type III potentiostat with GPES software. A three electrode system was used, in which the working and counter electrodes were both $1 \mathrm{~cm}^{2} \mathrm{Pt}$ flags, the working electrode bent at a $90^{\circ}$ angle to provide a flat surface for applying the mineral paste. All potentials were determined vs a $\mathrm{Ag} / \mathrm{AgCl}$ (0.1 $\mathrm{M}$ in Ethaline) reference electrode.

\section{Results and discussions}

Figure 1 shows the paste formed from grinding $63 \mathrm{mg}$ of galena with $106 \mathrm{mg}$ of Ethaline and the electrode configuration with the paint cast mineral. The advantage of this approach is that 
the fluidity of the paste can be controlled using the viscosity of the DES or via the loading of the mineral.

$a$

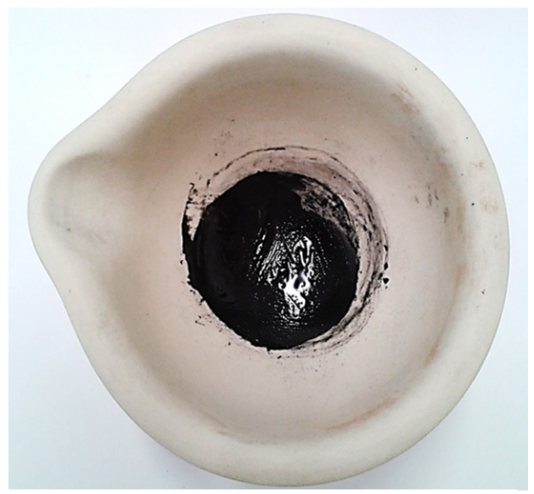

$b$

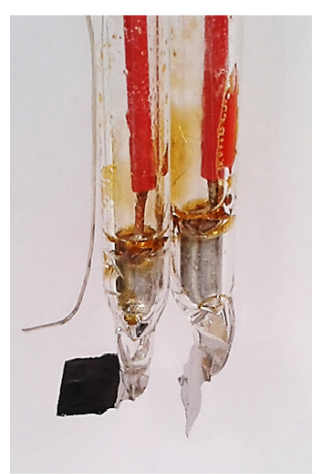

Figure 1: Figure la shows the paste of $63 \mathrm{mg}$ galena and $106 \mathrm{mg}$ of Ethaline, while figure $1 b$ shows the paste painted onto the surface of a Pt flag working electrode.

Figure 2a shows a voltammogram of galena painted on to a Pt electrode shown in Figure 1. When the coated electrode was immersed in the electrolyte (in this case also Ethaline) the mineral remained adhered to the electrode surface during and after immersion. Three anodic peaks can be seen (A1 to A3) and two cathodic peaks (C1 and C2). Starting with the potential at $0.0 \mathrm{~V}$ and scanning in a negative direction the peak $\mathrm{C} 2$ does not appear and $\mathrm{C} 1$ is small. $\mathrm{C} 1$ and $\mathrm{C} 2$ only become pronounced once the anodic sweep has gone beyond A3. It is proposed that $\mathrm{A} 3$ is due to the oxidation of $\mathrm{PbS}$ and $\mathrm{C} 2$ is due to the reduction of a species formed in this process. A3 must also release a lead species as the electrodeposition of lead can be assigned to $\mathrm{C} 1$ while $\mathrm{A} 1$ is the subsequent stripping of $\mathrm{Pb}$ (see below). The process was also attempted by making a paste of the mineral in Ethaline and immersing it in aqueous sodium chloride solution. The mineral paste remained on the electrode surface although the cyclic voltammogram was less well resolved as the aqueous solution did not wet the mineral well.

Figure $2 \mathrm{~b}$ shows the corresponding voltammograms to Figure $2 \mathrm{a}$ as a function of galena loading. It can be seen that that charge is related to the loading of the mineral showing that this could be the basis for a mineral assay. The layer thicknesses are in the range of 50 to 200 $\mu \mathrm{m}$ thick and in this range the voltammetric response is relatively unaffected by the thickness of the paste or the loading of the mineral.

Figure 2c shows a cyclic voltammogram of lead chloride powder (Sigma Aldrich) made into a paste with approximately the same particle size and mass loading as that for galena. It can be seen that two anodic processes (A4 and A5) and one cathodic process (C3) occur at 
approximately the same potentials as A1 and A2 on the anodic sweep and $\mathrm{C} 1$ on the cathodic sweep. The shapes of these peaks are characteristic of metal dissolution and deposition. Recent work by Liao et al. studied the electrochemistry of $\mathrm{PbSO}_{4}$ and $\mathrm{PbO}$ which are both soluble in Ethaline and the same shaped voltammograms were observed with peaks at the same potentials [14]. The peak at C3 was ascribed to lead deposition, A4 is bulk lead dissolution and $\mathrm{A} 5$ is the dissolution of a $\mathrm{Pb}-\mathrm{Pt}$ alloy. The peak at $\mathrm{C} 2$ is not observed for $\mathrm{PbSO}_{4}$ and $\mathrm{PbO}$ so can therefore be ascribed to the sulfur species in galena.
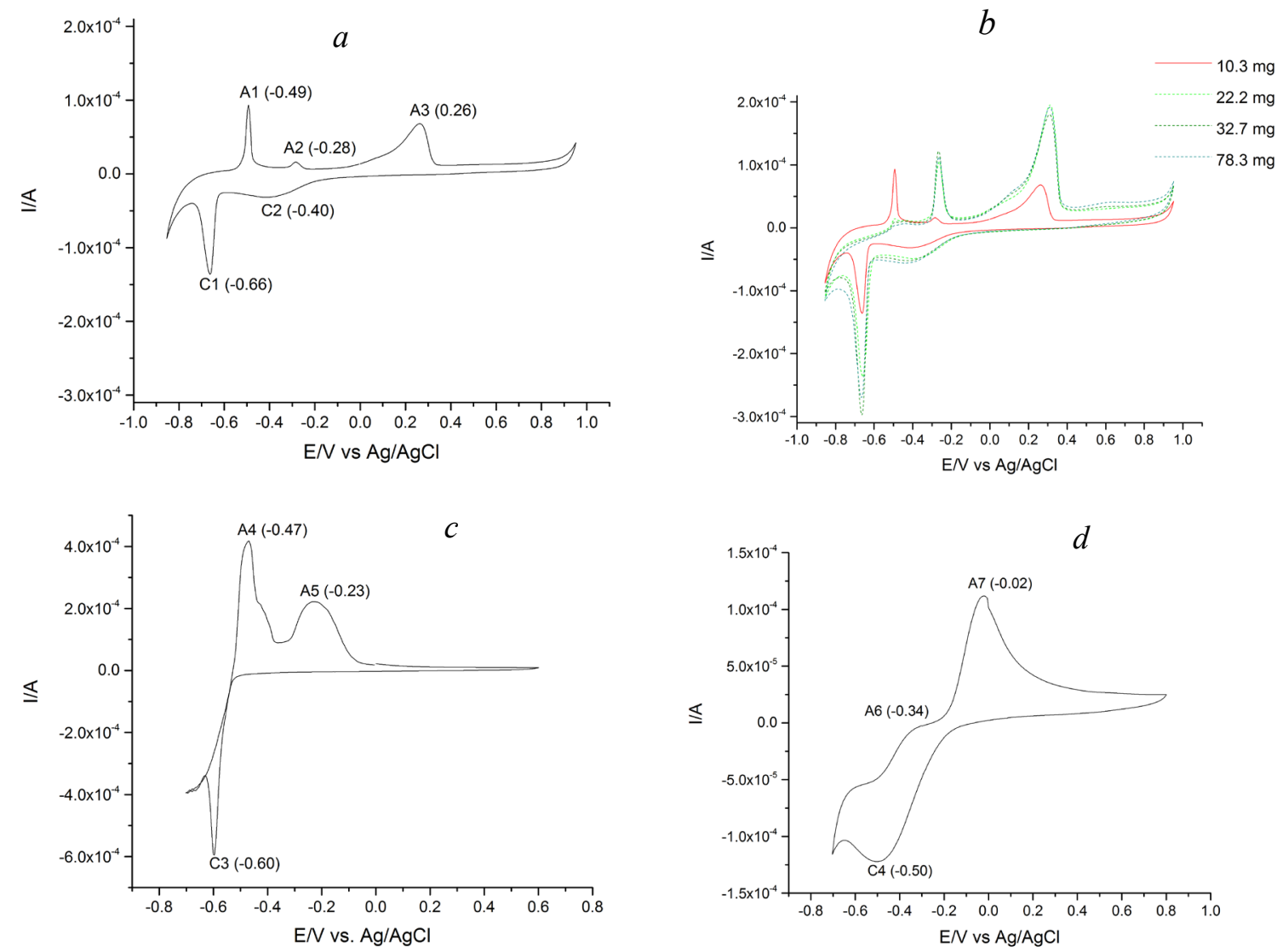

Figure 2: (a) voltammogram of $10.3 \mathrm{mg}$ of galena paste on a Pt electrode and (b) as a function of galena loading. (c) and (d) show the voltammograms of lead chloride and sulfur powders respectively prepared in the same method as Figure 1.

Figure $2 \mathrm{~d}$ shows that the technique can also be used for more electrically resistive materials such as sulfur. In this case yellow sulfur (Aldrich, reagent grade, 100 mesh) was used with Ethaline. This voltammogram shows one main anodic process, A7, and one cathodic process C4 with a shoulder A6 in the anodic sweep.

The cyclic voltammetry of a solution saturated with sulfur has also been reported by Manan et al. [15] who used glassy carbon, Au and Pt electrodes to study sulfur electrochemistry but 
using an ionic liquid, 1-butyl-3-methyl-imidazolium dicyanamide as the electrolyte. They saw a similar response to that shown in Figure $2 \mathrm{~d}$ although the cathodic signal was clearly separated into two signals on gold and GC whereas the two peaks overlapped more on Pt. They assigned the cathodic processes to

$3 \mathrm{~S}_{8}+8 \mathrm{e}^{-} \rightarrow 4 \mathrm{~S}_{6}^{2-}$

$2 \mathrm{~S}_{6}{ }^{2-}+2 \mathrm{e}^{-} \rightarrow 3 \mathrm{~S}_{4}^{2-}$

and proved this by synthesising $\mathrm{Na}_{2} \mathrm{~S}_{6}$ and $\mathrm{Na}_{2} \mathrm{~S}_{4}$ and comparing the optical properties of their solutions with that produced from the reduction of $\mathrm{S}_{8}$. It is proposed that $\mathrm{C} 4$ is an amalgamation of reactions 1 and 2 and A6 and A7 are the reoxidation processes. The charge on the anodic and cathodic sweeps are very similar $\left(\mathrm{Q}_{+}=5.1( \pm 0.1) \times 10^{-3}\right.$ and $\mathrm{Q}_{-}=$is $6.2( \pm$ $\left.0.1) \times 10^{-3} \mathrm{C}\right)$.

The lack of redox signals in Figure 2a corresponding to the potentials shown in Figure $2 \mathrm{~d}$ for sulfur oxidation and reduction seem to suggest that $\mathrm{A} 3$ is not the process

$\mathrm{PbS}-2 \mathrm{e} \rightarrow \mathrm{Pb}^{\mathrm{II}}+\mathrm{S}$

which was proposed by Cisneros-Gonzalez et al. [16] in aqueous solutions i.e. elemental sulfur in not produced by the galena oxidation process. Voltammetry also shows no evidence of passivation and observing the surface under a 3D optical microscope, clear bulk dissolution of the surface can be observed. Gardner and Woods studied the redox chemistry of a single crystal sample of galena in aqueous solutions as a function of $\mathrm{pH}$. It was found that in acidic $\mathrm{HClO}_{4}$ solutions anodic oxidation led to a soluble $\mathrm{Pb}$ species with a layer of amorphous sulfur forming on the electrode which restructures to become porous and enable further surface dissolution [17]. In basic solutions ( $\mathrm{pH} 6.8$ to 11) the principal product was lead oxide with some thiosulfate and sulfur. The voltammograms exhibit one anodic and one cathodic response both of which are irreversible in acidic solutions. The cathodic response becomes partially reversible in basic solutions.

The voltammetry of galena was also studied in aqueous solutions at $\mathrm{pH} 2$ using a carbon paste electrode by Cisneros-Gonzalez et al. [18] Scanning the potential in a positive direction first resulted in a large, irreversible oxidation process at $+0.6 \mathrm{~V}$ vs SCE which could be due to the oxidation of sulfide to sulfur followed by the formation of sulfate at higher anodic over-potentials. On the cathodic sweep a smaller, reversible redox process was observed at $0.5 \mathrm{~V}$ which was ascribed to $\mathrm{Pb}$ deposition and stripping, presumably released by the first oxidation process. The authors also showed the effect on the voltammetry from the addition 
of chloride ions to the solution and it was found that the anodic process became more resolved and its shape and potential became similar to that seen in Figure $2 \mathrm{a}$ [18]. The difference in oxidation potential between A1 and A3 is the same as that reported with aqueous $1.0 \mathrm{~mol} \mathrm{dm}^{-3}$ sodium chloride. Comparison of the redox potentials is difficult due to the different reference electrodes but the relative positions of the peaks are similar. The anodic peak A2 is missing from either of the aqueous studies as they did not use Pt as a current collector. The aqueous study did, however observe a quasi-passivation of the electrode due to the precipitation of insoluble $\mathrm{PbCl}_{2}$ which does not appear to occur in Ethaline. It is proposed that the oxidation of galena in a high chloride environment leads to a soluble $\mathrm{Pb}$ species with a sulfur ligand. The same behaviour has been observed for a variety of iron minerals including pyrite and marcasite [19].

To determine whether metallic $\mathrm{Pb}$ could be recovered from galena paste in Ethaline a bulk electrolysis experiment was carried out. A $30 \times 30 \times 35 \mathrm{~mm}$ cell made of acrylonitrile butadiene styrene was used. The cell is shown schematically in Figure 3a. A small volume 30 x $30 \times 5 \mathrm{~mm}$ was packed with a paste of galena in Ethaline sectioned off from the rest of the cell with a filter paper membrane; the cathodic cell compartment was filled with Ethaline. A titanium mesh anode was placed into the mineral paste and a nickel cathode was placed into the Ethaline 200. Bulk anodic electrolysis was carried out for 5 hours at a constant potential of $1.5 \mathrm{~V}$ which led to solubilisation of some of the material. Following electrolysis the nickel sheet cathode was rinsed with water and found to be coated with a grey layer as shown in Figure 3b. Analysis with EDX showed it was metallic lead with negligible sulfur or chloride.

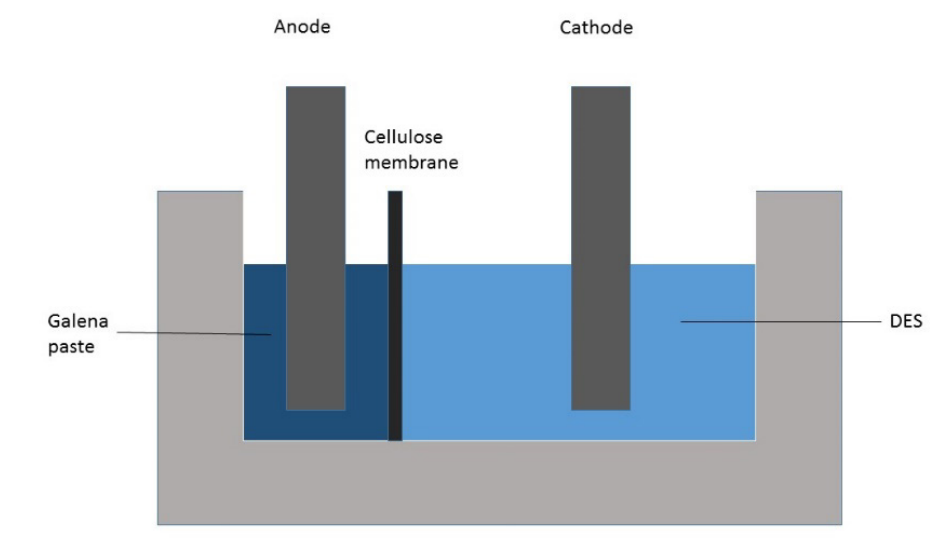

$b$

$a$

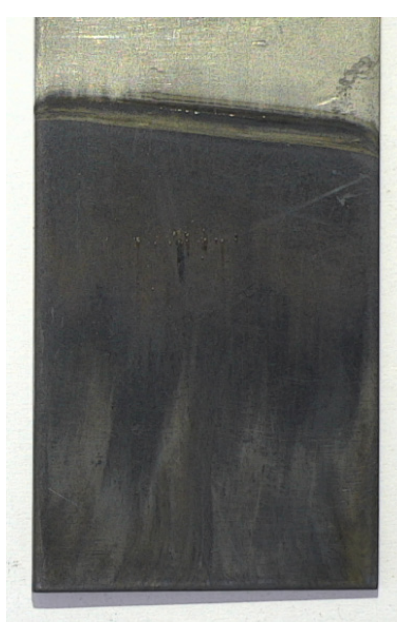

Figure 3: a) Schematic diagram of the electrolysis of galena paste in Ethaline at a constant potential of 1.5 V for 5 hours, b) Ni cathode surface after electrolysis. 


\section{Conclusions}

This study has shown that the electrochemical properties of conducting and semiconducting powders can be investigated using a paste of the material with an ionic liquid or DES and painting it onto an electrode surface. The mineral galena was studied in this case in Ethaline and it was shown that the electrochemical behaviour was clearly defined using this type of modified electrode. The use of a paint casting method was also shown to be simple method by which metal ions could be solubilised from a mineral and the metal recovered on the counter electrode in a pure state.

\section{Acknowledgements}

This work was supported by NERC Minerals Security of Supply (SoS) grant NE/M010848/1 Tellurium and Selenium Cycling and Supply (TeaSe). 


\section{References}

1 E. Ahlberg, J. Ásbjörnsson, Carbon paste electrodes in mineral processing: an electrochemical study of galena, Hydromet. 1993, 34,171-185.

2 T. Grygar, F. Marken, U. Schröder F. Scholz Electrochemical Analysis of Solids. A Review, Collect. Czech. Chem. Commun., 67 (2002) 163-208

3 A. Doménech-Carbó, M.T. Doménech-Carbó, F.M. Valle-Algarra, J.V. GimenoAdelantado, L. Osete-Cortina, F. Bosch-Reig, On-line database of voltammetric data of immobilized particles for identifying pigments and minerals in archaeometry, conservation and restoration (ELCHER database), Anal. Chim Acta, 927 (2016) 1-12

4 M. Armand, F. Endres, D. R. MacFarlane, H. Ohno, B. Scrosati, Ionic-liquid materials for the electrochemical challenges of the future, Nature Mat. 8 (2009) $621-629$.

5 A. P. Abbott, G. Frisch, K. S. Ryder, Electroplating using Ionic liquids, Ann. Rev. Mat. Res. 43 (2013) 1.1-1.24.

6 A. P. Abbott, G. Capper, D. L. Davies, R. Rasheed, V. Tambyrajah, Novel Solvent Properties of Choline Chloride/ Urea Mixtures, Chem. Commun, (2003) 70-71.

7 E. L. Smith, A. P. Abbott K. S. Ryder, Deep Eutectic Solvents (DESs) and their applications, Chem. Rev. 114 (2014) 11060-82.

8 F. Endres, A. P. Abbott, D. MacFarlane, "Electrodeposition of Metals from Ionic Liquids" Wiley, Weinheim, VCH, (2008).

9 G. R. T. Jenkin, A. Z. M. Al-Bassam, R. C. Harris, A. P. Abbott, D. J. Smith,. D. A. Holwell, R. J. Chapman, C. J. Stanley, The application of deep eutectic solvent ionic liquids for environmentally-friendly dissolution and recovery of precious metals, Minerals Engineering, 87 (2016) 18-24

10 A. P. Abbott, G. Frisch, J. Hartley, K.S. Ryder, Processing of metals and metal oxides using ionic liquids, Green Chem., 13 (2011) 471-481.

11 R.L. Paul, M.J. Nicol, J.W. Diggle, A.P. Saunders, The electrochemical behaviour of galena (lead sulphide) - I. Anodic dissolution, Electrochim. Acta, 23 (1978) 625-633.

12 M.J. Nicol, R.L. Paul, J.W. Diggle, The electrochemical behaviour of galena (lead sulphide) - II. Cathodic reduction, Electrochim. Acta, 23 (1978) 635-639.

13 J.L. Nava, M.T. Oropeza, I. González, Electrochemical characterisation of sulfur species formed during anodic dissolution of galena concentrate in perchlorate medium at pH 0, Electrochim. Acta, 47 (2002) 1513-1525 
14 Y-S. Liao, P-Y. Chen, I-W. Sun, Electrochemical study and recovery of $\mathrm{Pb}$ using 1:2 choline chloride/urea deep eutectic solvent: A variety of $\mathrm{Pb}$ species $\mathrm{PbSO}_{4}, \mathrm{PbO}_{2}$, and $\mathrm{PbO}$ exhibits the analogous thermodynamic behaviour, Electrochim. Acta, 214 (2016) 265-275.

15 N.S.A. Manan, L. Aldous, Y. Alias, P. Murray, L.J. Yellowlees, M.C. Lagunas, C. Hardacre, Electrochemistry of sulfur and polysulfides in ionic liquids, J. Phys. Chem. B, 115 (2011) 13873-13879.

16 I. Cisneros-González, M.T. Oropeza-Guzmán I. González, Cyclic voltammetry applied to the characterisation of galena, Hydromet. 53 (1999) 133-144.

17 J. R. Gardner R. Woods, A study of the surface oxidation of galena using cyclic voltammetry, J. Electroanal. Chem. 100 (1979) 447-459

18 I. Cisneros-González, M.T. Oropeza-Guzmán I. González, An electrochemical study of galena concentrate in perchlorate medium at $\mathrm{pH}$ 2.0: the influence of chloride ions, Electrochim. Acta 45 (2000) 2729-2741

19 A. P. Abbott, A. Z. M. Al-Bassam, A. Goddard, R. C. Harris, G. R. T. Jenkin, F. Nisbett, M. Wieland, Pyrite Dissolution using Deep Eutectic Solvent, in preparation 